\title{
MÉTODO DA ECONOMIA POLÍTICA - ALGUMAS INDICAÇÕES PARA UMA REFLEXÃO SOBRE A PESQUISA EM EDUCAÇÃO
}

\author{
ROSA MARIA CORREA DAS NEVES ${ }^{1}$ \\ SIOMARA BORBA ${ }^{2}$
}

\begin{abstract}
RESUMO
Apresentamos uma discussão sobre o processo de conhecimento científico, considerando notas metodológicas de parte da produção teórica de Karl Marx (1974), notas que podem indicar contribuições para o desenvolvimento de pesquisas científicas em educação. A discussão que se apresenta se refere à pesquisa teórica que, partindo de notas metodológicas marxianas, buscou nos trabalhos de Miriam Limoeiro Cardoso (1977, 1990) posições a respeito do "método científico correto" como sugerido por Marx, a partir das suas críticas ao método da economia política clássica, uma vez que Marx (1974) dá início ao processo de conhecimento da produção material capitalista a partir da crítica ao método dos economistas clássicos em seus processos de conhecimento da produção econômica. O método científico de economistas liberais inicia pelo real, entendido como empírico, e realiza conclusões através da produção de abstrações de caráter simples e geral, abstrações suficientes como explicação da produção material. Retificando esse método, Marx afirma que o "método científico correto" começa pelo abstrato e alcança um conhecimento concreto ao tratar a realidade como "síntese de múltiplas determinações". Cardoso (1977, 1990), a partir da crítica de Marx (1974) ao método de conhecimento dos economistas clássicos, explicita que o "método científico correto" é aquele que começa no conhecimento abstrato, teórico, buscando o conhecimento concreto sobre a realidade através do conhecimento de suas determinações. É o destaque dado às determinações que constrói o conhecimento sobre a realidade como um "concreto de pensamento". Embora toda a crítica que Marx (1974) fez ao método científico da economia clássica não diga respeito ao conhecimento em geral, o argumento de negação da realidade identificada pelos sentidos e de sua afirmação como a "síntese de múltiplas determinações" - determinações que afetam os sujeitos em sociedade e que são reconhecidas no pensamento - é fundamental na defesa de opções teórico-metodológicas que entendem que o trabalho de pesquisa é um trabalho de construção teórica do objeto de conhecimento, trabalho em que a atividade teórica faz da realidade um objeto científico, destacando as determinações que o fazem "concreto de pensamento".
\end{abstract}

PALAVRAS-CHAVES: Conhecimento Científico; Questões Teórico-Metodológicas; Karl Marx; Miriam Limoeiro Cardoso; Construção Teórica do Objeto.

\footnotetext{
ABSTRACT

It is presented a discussion about the process of scientific knowledge, considering methodological notes of the theoretical work of Karl Marx (1974), notes that may indicate contributions to the development of scientific research in education. The discussion that emerges and that refers to theoretical research, from Marxian methodological notes, sought in the work of Miriam Limon Cardoso $(1977,1990)$ position regarding the "correct scientific method" as suggested by Marx, from his criticism of the method of classical political economy,

${ }^{1}$ Rosa Maria Correa das Neves é doutora em Educação pela Universidade do Estado do Rio de Janeiro e professora adjunta da Universidade Federal do Rio de Janeiro (UFRJ)

${ }^{2}$ Siomara Borba é doutora em Educação pela Pontifícia Universidade Católica do Rio de Janeiro e professora associada da Universidade do Estado do Rio de Janeiro (UERJ)
} 
once Marx (1974) begins the process of knowledge of capitalist material production from the criticism of the method of the classical economists in their knowledge processes of the economic production. The liberal economists' scientific method starts by the real, understood as empirical, and reach conclusions by producing abstractions of simple and general character, abstractions enough as explanation of material production. Rectifying this method, Marx asserts that the "correct scientific method" begins by the abstract and reaches a concrete knowledge when dealing with reality as "a synthesis of multiple determinations". Cardoso (1977, 1990), from the critique of Marx (1974) to the method of knowledge of the classical economists, explains that the "correct scientific method" is the one that begins in the abstract, theoretical knowledge, seeking the concrete knowledge over a reality through the knowledge of its determinations. It is the prominence given to determinations that builds knowledge over reality as a "concrete thinking". Although all the criticism that Marx (1974) did to the scientific method of classical economics does not relate to the knowledge in general, the argument of denial of reality identified by the senses and its claim as the "synthesis of multiple determinations"determinations that affect the subject in society and are recognized in the thought - is paramount in the defense of theoretical and methodological choices which understands that the search work is a theoretical construction work of the knowledge object, work on which the theoretical activity creates from reality a scientific object, highlighting the determinations that makes it "concrete thinking".

KEYWORDS: scientific knowledge, theoretical and methodological issues; Karl Marx; Miriam Limoeiro Cardoso; theoretical construction of the object.

\section{Introdução}

Nosso objetivo é apresentar discussão que examinou a fecundidade metodológica para o campo da educação a partir de notas metodológicas da produção teórica marxiana sobre a sociedade capitalista, notas que tiveram como objetivo produzir conhecimento sobre a realidade social. Entendemos que as críticas teóricometodológicas de Marx contêm orientações teórico-metodológicas que podem contribuir na produção do conhecimento científico e objetivo da realidade social e indiretamente no desenvolvimento das pesquisas em educação. Tendo processos de investigações em educação como horizonte de preocupação, consideramos importante "entender a dialética materialista nas suas proposições, na sua capacidade explicativa e nas suas limitações para operar na pesquisa da realidade" (Cardoso, 1990, p. 1). Marx (1974) afirma sua preocupação com o processo de conhecimento da produção material. Mas, ao discutir o método de conhecimento da produção material, apresenta posições que, de forma direta ou não, podem ser entendidas como orientações para o método de conhecimento da realidade em geral. Ao mesmo tempo em que entendemos que as posições teórico-metodológicas construídas no esforço crítico marxiano significam contribuição essencial no desenvolvimento de pesquisas sobre a realidade social, afirmamos que tais posições são gerais sobre o trabalho científico e necessitam ser concretizadas em relação a cada objeto de pesquisa específico, no que se inclui a educação enquanto objeto científico.

Para iniciar a discussão do conhecimento sobre a realidade econômica produzido pela economia política, Marx (1974, p. 211. grifos do autor) afirma no início da introdução que "O objeto desde estudo é, em princípio, a produção material." Toda a preocupação de Marx (1974), nesse texto e em outros momentos de sua obra, é com a questão da produção material. A crítica que Marx (1974) faz ao método de conhecimento é ao método de conhecimento da produção material como foi desenvolvido pelos economistas liberais e suas posições a respeito do método correto de conhecimento dizem respeito ao método de conhecimento da produção material. Portanto, não encontramos, nesse trabalho específico, nem sugestões epistemológicas

\begin{tabular}{|l|l|l|l|l|}
\hline Gexista Dialectus & Ano 2 & n.5 & Agosto - Dezembro 2014 & p.140 - 150
\end{tabular}


gerais, nem sugestões epistemológicas para uma área de conhecimento específica que possam ser diretamente transpostas para o conhecimento sobre a realidade social de forma abstrata. Interpretar a obra de Marx (1974), buscando orientações gerais, significa negar o pressuposto epistemológico de crítica da generalidade, da abstração simples e vazia.

Nossa direção de estudos tem como referência notas metodológicas de parte da produção teórica de Karl Marx (1974), leitura que se completa pela sua interpretação por Miriam Limoeiro Cardoso (1977 e 1990) e nos serve para pensarmos a questão do conhecimento científico. Outros pensadores, dentre eles José Paulo Neto e Eduardo Ferreira Chagas ${ }^{3}$, têm examinado as notas metodológicas de Marx na crítica ao método da economia política, produzindo análises que aqui não consideramos. Nossa contribuição tem fundamento nos argumentos de Cardoso expostos principalmente em suas publicações de 1977 e 1990, nas quais a autora sumariza seu aprendizado teóricometodológico, subsidiário de sua própria produção científica.

Certamente, encontramos alguns comentários teórico-metodológicos que podem nos orientar no sentido de pensar o processo de conhecimento da realidade social a partir dos pressupostos da teoria marxista de sociedade. Cardoso $(1977,1990)$ entende que é possível encontrar indiretamente na "Introdução" as teses que Marx (1974) afirma como fundamentais para o conhecimento da realidade social, reconhecendo a "Introdução" como "um texto dedicado a reflexões metodológicas de relevância inquestionável" e o item III - Método da Economia Política - "como um dos textos fundamentais da obra de Marx". (Cardoso, 1990, p. 2)

Como o objetivo do nosso trabalho é comentar a discussão de Marx sobre o método da economia clássica com o auxílio da análise de Cardoso (1977, 1970), chamando a atenção para a questão teórico-metodológica, seguiremos o esquema da apresentação de Marx (1977), começando pela construção teórica do objeto que vai nos permitir inferir o método científico em uma perspectiva marxiana.

\title{
Questões teórico-metodológicas do conhecimento científico: a discussão teórica como ponto de partida.
}

Um conhecimento se constitui como científico quando define um aspecto da realidade como seu objeto e é capaz de construir uma explicação que seja rigorosa, consistente, lógica e racional e que apreenda o objeto investigado sem contradições e fragilidades teórico-conceituais. Essa explicação sobre o conhecimento científico é formulada por Cardoso (1977, p. 1), em sua problematização sobre a periodização na ciência da História:

\begin{abstract}
A História se constitui como ciência quando formula seu objeto e constrói para ele uma explicação capaz de resistir a procedimentos de prova reconhecidos, podendo sustentar-se por uma demonstração rigorosa, que, ao mesmo tempo, é lógica, racional, e dá conta efetivamente dos fatos da história real.
\end{abstract}

Tal afirmação permite concluir que a condição de cientificidade de um conhecimento não está no método como tradicionalmente tem sido sugerido - um

\footnotetext{
${ }^{3}$ A discussão metodológica marxiana desses autores está em PAULO NETTO, J. Introdução ao Estudo do Método de Marx. São Paulo: Expressão Popular, 2011 e em CHAGAS, E. F. O método dialético de Marx. In: JIMENEZ, S.; OLIVEIRA, J. L. de e SANTOS, D. (Orgs). Marxismo, educação e luta de classes: teses e conferências do II Encontro Regional Trabalho, educação e formação humana. Fortaleza: EdUECE/IMO/SINTSEF, 2008, p. 45-62 e CHAGAS, E. F. O método dialético de Marx: investigação e exposição crítica do objeto. In Síntese - Revista de Filosofia, v. 38, no. 120, 2011, p. 55-
} 70. 
conjunto articulado de técnicas -, mas na possibilidade de tratar racionalmente o objeto real, de converter o real em objeto de investigação crítica. Segundo Cardoso (1977, p. 1), "o que determina a possibilidade ou não de ser [...] uma ciência: [é] a questão da racionalidade do seu objeto". Essa afirmação se sustenta na tese de que a realidade tratada como objeto científico implica uma lógica que lhe é particular e que somente o processo racional permite capturar. Essa lógica, por sua vez, não é revelada pela própria realidade ou descoberta através da reconstituição de suas manifestações sensíveis ou de relação entre essas manifestações como se pressupõe em uma epistemologia cientificista, mas será construída através de um trabalho crítico no conhecimento de suas determinações, segundo a perspectiva epistemológica fundada nos pressupostos da teoria marxiana de conhecimento.

Conhecer a realidade sem buscar as suas determinações, aspecto central na teoria marxista, significa conhecer essa realidade pelos seus estados e dinâmicas caóticas, pelas manifestações subjetivas das vontades individuais, pelos modelos ideais, pelos seus fragmentos. Supor que é possível tratar da realidade partindo de subjetividades, de fragmentos e de um padrão ideal nos conduz a uma perspectiva necessariamente caótica e, no limite, a descrições parciais da realidade ou a defesa do que deveria ser a realidade, mas não permite explicar a realidade social. Nesse sentido, discutindo a História como ciência e o conhecimento científico do fato histórico, Cardoso (1977, p. 1-2) argumenta sobre a necessidade de identificação das determinações sociais, sem as quais a realidade social é caótica, fragmentada e produto de subjetividades individuais:

É necessário definir a hipótese básica de se o real de que trata a história
possui, enquanto realidade humana, e, portanto social, uma racionalidade. Se
o social, como tal, não tem uma organização própria, se é caótico, se se forma
e se transforma ao sabor das subjetividades das vontades individuais, a
história não pode ser senão biografia generalizada, ou no máximo ilustrada
por modelos ideias. Nunca irá além do descritivo, com maior ou menor
riqueza de detalhes, com maior ou menor sistematicidade e espírito
classificatório, acompanhada ou não por padrões gerais que servem para
medi-la e também para julgá-la. Neste caso, a explicação do objeto
demonstrada e evidenciada, respondendo porque ele é como é ou foi como
foi, é inatingível. A cognoscibilidade do objeto histórico supõe algum tipo de
determinação que lhe seja peculiar. O conhecimento histórico só é produzido
quando as determinações do seu objeto são apreendidas, explicando por elas
o que elas determinam.

Ao afirmar a importância das determinações, enfatizando sua apreensão como condição para o conhecimento científico sobre a realidade histórica, Cardoso (1977) chama a atenção para a necessidade de interrogar as próprias determinações, seu caráter e para os processos que permitem chegar a tais determinações, possibilitando o conhecimento científico sobre a realidade. Conhecendo o significado dessas determinações, é possível se aproximar da realidade entendida em sua lógica própria e não mais como fatos mais ou menos isolados, individuais, particulares e específicos, fatos que se formariam a partir de um conjunto de fragmentos, de "pedaços" do real.

$\mathrm{Na}$ tentativa de conhecer a realidade, o processo investigativo pode partir do pressuposto de que cada fato "tem um valor em si mesmo, porque seu sentido está dentro dele próprio" (Cardoso, 1977, p. 2). Nessa perspectiva, esse fato deve e pode ser separado de outros fatos com o objetivo de garantir o seu conhecimento. Tal atitude significa que esse fato é entendido como produto único, embora inequivocamente todo fato seja "produto de seus agentes e circunstâncias." (Ibidem). Contudo, se aceitarmos o pressuposto de que a realidade social tem uma lógica, essa não pode ser construída pela "individualidade absoluta dos fatos" (Cardoso, 1977, p. 4) e nem pelos "traços comuns

\begin{tabular}{|l|l|l|l|l|}
\hline Govista Qialectus & Ano 2 & n.5 & Agosto - Dezembro 2014 & p.140 - 150 \\
\hline
\end{tabular}


que possam ser detectados entre eles", mas é engendrada pelas "determinações das totalidades concretas, que são históricas". (Cardoso, 1977, p. 4)

A partir dessas indicações iniciais sobre o que define o conhecimento científico, o exame de notas metodológicas de Marx (1974) nos permite reconhecer sua importância e riqueza teórica, estando cientes ao mesmo tempo de que somente através dessas notas não se esgota o alcance da profundidade teórica marxiana.

$\mathrm{Na}$ perspectiva da teoria marxiana da sociedade capitalista, o início metodológico correto exige começar pelo conhecimento teórico. Essa trajetória é totalmente diferente daquela que pode ser tomada como um senso comum sobre o conhecimento científico segundo o qual é científico o conhecimento que parte da realidade e exige investigações que, começando pelo trabalho metódico sobre a realidade em suas manifestações sensíveis, traduziriam teoricamente a própria realidade em exame. As posições sobre o processo investigativo que apreendemos no esforço de explicação da economia capitalista por Marx é totalmente contrário a esse senso científico comum. Marx (1974) inicia seu método de investigação pela discussão do conceito de produção material conforme exposto na produção teórica de economistas clássicos, identificando as suas insuficiências e inconsistências, no plano da história e da sociedade.

Ao analisar a produção material nas condições da sociedade capitalista, Marx (1974) começa pela crítica à construção do objeto - produção material - feita pelos economistas clássicos e "vai indicando as linhas mestras da construção que ele próprio empreenderá" (Cardoso, 1990, p. 4). Ainda que as notas metodológicas marxianas apresentem "apenas em esboço, suas preocupações metodológicas mais fortes" (Cardoso, 1990, p, 4), Cardoso (1990, p. 4) afirma que a parte I da "Introdução", que trata da produção material, é muito importante de ser considerada quando a proposta é discutir a questão do conhecimento sobre a realidade porque "estão aí indicadas [...] algumas [das teses de Marx] mais básicas e mais gerais"

Marx (1974) começa seu trabalho, explicitando, claramente, que o objeto do seu estudo é a produção material. Para examiná-la, Marx (1974) diz que é preciso partir do pressuposto central à existência da humanidade: toda produção é uma produção de indivíduos socialmente determinados. Nas palavras de Marx (1974, p. 211), "Indivíduos produzindo em sociedade - portanto uma produção de indivíduos socialmente determinada, este é, naturalmente, o ponto de partida". Essa determinação fundamental da explicação econômica elaborada por Marx é desde já uma contraposição àquela explicação dos economistas clássicos, sobre a qual Marx (1974) empreende exame, e evidenciando desde aí que seu método no trabalho científico inicia com a crítica teórica. Em diferença ao entendimento dos economistas até então, Marx (1974) afirma que para o conhecimento sobre a realidade econômica não se pode partir de indivíduos isolados. Para Marx (1974), os economistas clássicos, ao buscarem explicar a produção material na sociedade burguesa partiram do entendimento de que, antes da sociedade burguesa, existiam homens produzindo suas condições de sobrevivência de modo isolado, de modo natural. Esse modelo para a produção - que vê o homem isolado e produzindo individualmente para atendimento as suas necessidades imediatas - para os economistas liberais, é o começo da história. Ao negar a possibilidade de existência de uma forma de produção isolada, individual e natural e dessa forma produtiva ser uma forma de produção inicial da humanidade, Marx (1974) afirma definitivamente o caráter social da produção.

Outra crítica teórica de Marx (1974) faz menção à análise dos economistas clássicos sobre a produção material e ao pressuposto de que existe produção em geral, produção fora de uma sociedade, sendo possível realizar um tratamento abstrato de uma realidade social que é a produção material. Na análise que Marx (1974) faz do objeto

\begin{tabular}{|l|l|l|l|l|}
\hline Govista Qialectus & Ano 2 & n.5 & Agosto - Dezembro 2014 & p.140 - 150 \\
\hline
\end{tabular}


produção material, destacamos sua ênfase e a insistência na posição de que a produção material sendo uma ação própria da existência humana, é necessariamente histórica e social, uma vez que a existência humana é histórica e social. Dessa crítica, se compreende que não é possível tratar o humano como particularidade atomizada no indivíduo, assim como não é possível tratar o humano como natural, sendo tudo relativo a humanidade de caráter histórico e social, sendo as sociedades produto dos homens em relação histórico-social. Essa advertência nega a possibilidade de compreender sociedades, como entendem os economistas liberais, como resultado de indivíduos isoladamente produzindo suas condições de sobrevivência.

Cardoso (1990, p.8) refere-se às conclusões da crítica teórica de Marx sobre o caráter histórico e social da produção material nos termos "particularidade histórica da produção" e "particularidade social da produção", termos com implicações metodológicas na produção teórica do próprio Marx, produção que considerando essas notas críticas, se coloca em radical oposição à análise dos economistas clássicos que trabalham com os conceitos de "produção em geral" e "produção geral".

Por "particularidade histórica da produção" (Idem, ibidem), Cardoso (1990) entende que Marx (1974) está negando a possibilidade da existência de uma produção em geral, que conteria dinâmicas e aspectos desde sempre permanentes, bem como a possibilidade de indivíduos isoladamente produzirem suas condições de sobrevivência material. Nesse sentido, Cardoso (1990, p. 8), resumindo o pensamento de Marx (1974), afirma: "Não há produção em geral. Os indivíduos vivem e produzem em sociedade. Ao falar da sua produção, fala-se da produção de uma sociedade determinada, num momento determinado do seu desenvolvimento"

Em continuidade, passa a ser central no trabalho científico de Marx (1974) sua perspectiva de que a realidade social é dinâmica, se transforma, é transformada pela humanidade, sendo a história das sociedades a possibilidade e a condição para o entendimento da realidade das próprias sociedades. Pensamos que reside sobre o caráter histórico das sociedades e, no plano metodológico, sobre a "particularidade histórica da produção", a diferença teórica e metodológica fundamental entre a economia clássica e a economia marxiana, diferenciando o pensamento abstrato e simples do concreto. É exatamente essa diferença que admite como possível compreender que há uma ordem natural de fatos que podem evoluir, certamente, mas segundo uma natureza que permanece ${ }^{4}$. Nas notas metodológicas de Marx, a crítica da naturalidade na produção teórica sobre a produção pelos economistas clássicos incide sobre os conceitos de indivíduo e de propriedade, conceitos e realidades econômicas que seriam eternas. Segundo essa compreensão, a existência humana, e mesmo suas criações e suas modificações, tem origem e se desenvolve a partir de uma evolução natural da humanidade, sendo toda existência humana uma possibilidade dada pela natureza e por uma história essencialmente genética.

Tratar o movimento da existência humana como uma condição natural é um entendimento que separa a economia liberal da economia marxista. A análise que Marx (1974) fez do objeto produção material está fundada na história das relações sociais e de suas relações de produção. Essa análise afirma que as possibilidades de ser, criar e modificar são históricas, construídas por uma determinada forma de organizar a produção material.

Esse entendimento tem implicações imediatas na questão do conhecimento sobre a realidade, significando, por um lado, a negação da possibilidade de produzir conhecimento sobre a produção material a partir da identificação de elementos

${ }^{4}$ Nas notas metodológicas de Marx, a crítica da naturalidade da produção teórica dos economistas clássicos incide sobre os conceitos de indivíduo e de propriedade que seriam eternos.

\begin{tabular}{|l|l|l|l|l}
\hline Q Rovista Dialectus & Ano 2 & n.5 & Agosto - Dezembro 2014 & p.140 - 150
\end{tabular}


recorrentes, portanto, gerais e abstratos, elementos que poderiam ser identificados na manifestação aparente da dinâmica da produção material; por outro lado, significa afirmar a possibilidade de produzir conhecimento sobre a produção material ao considerar as condições históricas, as condições que podem explicar a dinâmica das relações econômicas e, consequentemente, as sociedades.

Essa diferença assinalada por Marx, por outro lado, é exemplar de seu trabalho teórico e uma demonstração clara de seu método científico, do "método científico correto" entendendo correto como resultado da correção dos problemas teóricometodológicos profundos e típicos das teorias disponíveis em sua época para o estudo do capitalismo. Enfatizamos que o conhecimento científico sobre o capitalismo do século XIX produzido por Marx inicia pelo trabalho teórico e que, com sua crítica teórica, a dimensão histórica e social da produção material, dimensão que supõe que nenhum aspecto particular da produção - o indivíduo ou a propriedade ou ainda outra condição - é natural ou determinado por uma natureza econômica, é o que lhe permite afirmar que a determinação da produção material se relaciona à dinâmica histórica das sociedades e a buscar compreender as relações sociais típicas do modo de produção capitalista, modo histórico de produção material em sociedades específicas.

\section{Questões teórico-metodológicas do conhecimento científico: alguns aspectos da discussão metodológica}

Segundo Cardoso (1990), o conhecimento científico sobre a realidade social supõe a definição de um método de pesquisa. Para se ter acesso às possibilidades metodológicas para a investigação sobre a realidade social, existem dois caminhos. Um deles, é o estudo dos textos que apresentam e tratam a metodologia como objeto de ensino - são os textos sobre metodologia e técnicas/instrumentos de ensino. $\mathrm{O}$ outro caminho corresponde a um trajeto indireto: o método é apreendido a partir do desenvolvimento teórico alcançado: "por meio do estudo das formulações teóricas alcançadas pela utilização prática do método em questão." (Cardoso, 1990, p. 1).

No entanto, embora os dois caminhos possam se completar e, portanto, contribuírem para a produção do conhecimento sobre a realidade, a análise que Marx (1974) fez sobre a produção material, entendida como momento complexo e determinante que compreende não só o processo produtivo propriamente dito, mas o consumo, a distribuição e a troca, antes de apresentar sua discussão sobre o método da economia política, ressalta o lugar privilegiado da teoria na discussão metodológica.

Para criticar o método da economia burguesa, Marx (1974, p. 229) apresenta, inicialmente, a questão do processo de produção econômica para em seguida falar sobre o método de investigação da economia política clássica e sobre o que ele reconhece como o "método científico correto."

No campo teórico do marxismo, como vimos na discussão do significado de ciência apresentada por Cardoso (1977), um ponto importante na discussão que diz respeito à produção de conhecimento sobre a realidade social é a crítica a alguns postulados, dentre eles, o pressuposto que o conhecimento sobre a realidade social, em todas as suas dimensões, começa pela identificação e reconhecimento sensível, subjetivo e particular do real e termina na apresentação de uma explicação abstrata do real, quando o real com suas formas, qualidades e particularidades, com suas marcas imediatas, com suas determinações desaparece dando lugar a um conhecimento que conhece sobre a realidade, no pensamento. 
O método de investigação, discutido por Marx, cuja preocupação é somente com o conhecimento da realidade econômica, com a economia política e, portanto, não tem nenhum compromisso com a discussão teórico-metodológica para o conhecimento da realidade social, ou seja, não está preocupado com as questões teórico-metodológicas das outras ciências da sociedade ${ }^{5}$, vai numa direção totalmente oposta ao método de conhecimento pensado pela concepção empirista de conhecimento.

Marx (1974) apresenta seu método nos seguintes termos: o método científico correto é o método que começa pela abstração simples e não pelo real aparente, como pensa a epistemologia dos economistas clássicos, e constrói, a partir das condições históricas concretas, uma abstração complexa, geral que, segundo, Marx (1974) é o "concreto de pensamento". Nesse modelo, não é o real que me diz o que ele é. São as condições concretas, as determinações do real que explicam o real, o real que, considerado a partir delas, se torna concreto e, no processo de conhecimento, se torna "concreto de pensamento". Assim, para Marx (1974, p. 228), o método científico correto inicia o conhecimento sobre o real pelo abstrato e não pelo aparente, para chegar ao entendimento concreto da realidade, na medida em que isso significa chegar ao conhecimento sobre a realidade tratada com suas determinações históricas, que não são aparentes, mas reconhecidas pelo pensamento:

O concreto é concreto por ser a síntese de múltiplas determinações, logo,
unidade da diversidade. É por isso que ele é para o pensamento um
processo de síntese, um resultado, e não um ponto de partida, apesar de ser o
verdadeiro ponto de partida e, portanto igualmente o ponto de partida da
observação imediata e da representação. O primeiro passo reduziu a plenitude
da representação a uma determinação abstracta; pelo segundo, as
determinações abstractas conduzem à reprodução do concreto pela via do
pensamento.

Segundo Cardoso (1977, 1990), o texto de Marx (1974) sobre o método da economia política, centrado no conhecimento da produção material, da economia, está organizado da seguinte forma: em um primeiro momento, Marx trata a questão do método em geral, entendido como um procedimento teórico, que se realiza no plano do abstrato; em decorrência desse pressuposto, Marx afirma a anterioridade do concreto frente ao real; essa afirmação leva à discussão sobre a relação entre o real e o teórico que significa, nos termos da teoria marxista, a relação entre categorias mais simples e categorias mais concretas; considerando as categorias concretas, categorias produzidas por abstrações mais gerais, elas são possíveis "a partir do desenvolvimento concreto mais rico", nas palavras de Cardoso (1977, p. 12); ao afirmar a importância "do desenvolvimento concreto mais rico" (Ibidem) para a "produção de abstrações mais gerais" (Ibidem), Marx, na leitura de Cardoso (1977), reconhece que é no momento histórico do modo de produção já consolidado, ou seja, no momento do modo de produção "mais complexo, rico e variado" (p. 12) é que é possível produzir a inteligibilidade dessa sociedade e das sociedades anteriores; e, por último, Marx discute a ordem das categorias. Essa ordem é dada por uma hierarquia teórica e não por sua

5 A contribuição de Marx de modo geral é vinculada à sociologia mas consideramos que essa classificação corresponde a uma compreensão reduzida da contribuição teórica de Marx e também de Engels uma vez que a análise social marxiana e engelsiana não pode estar apartada da realidade econômica mais geral na qual formas sociais se dinamizam, realidade que por sua vez precisa ser analisada concretamente, na sua dinâmica histórica. Outra distinção fundamental entre a teoria sociológica nascente, no século XIX, e a produção teórica de Marx e Engels reside no fato de que a primeira tem uma orientação reacionária e Marx e Engels, revolucionária, cumprindo a analise social um papel estratégico na organização de operários no século XIX.

\begin{tabular}{|l|l|l|l|l|}
\hline Rovista Dialectus & Ano 2 & n.5 & Agosto - Dezembro 2014 & p.140 - 150 \\
\hline
\end{tabular}


construção histórica, por sua evolução e acumulação teóricas, ou seja, as categorias capazes de contribuir para a construção do entendimento do mundo são as categorias mais simples, construídas com base em abstrações mais gerais, possíveis no modo de produção mais avançado.

Começando, então, pelo entendimento de que o conhecimento do mundo se faz no campo do teórico e da abstração, ou seja, que o método de conhecimento do mundo é teórico, Marx (1974), segundo Cardoso (1977, 1990), apresenta dois métodos: um deles é o método tradicional que foi seguido pela economia política ao longo de sua história. Esse método está fundado no pressuposto que o conhecimento parte do real para chegar ao abstrato. E um segundo método, que é uma continuação do primeiro, na medida em que trabalha com os resultados apresentados pelo método tradicional, mas que, ao mesmo tempo, "é apresentado como sendo construído a partir da identificação dos equívocos do primeiro e de sua crítica". (Cardoso, 1977, p. 13).

Para Cardoso (1977, 1990), no entendimento de Marx, os economistas clássicos começaram o processo de conhecimento pelos fenômenos e fatos imediatos, aparentes, confundindo o concreto com o real, partindo de categorias abstratas - realidade imediata e aparente - para tentar chegar a categorias simples - conhecimento abstrato e geral sobre a realidade, que foi subtraída de suas marcas de historicidade. Esse método tem como pressuposto, que lhe garante a tranquilidade de alcançar a "verdade" sobre o real, a segurança de ser um método objetivo, que está sustentado no pressuposto de que a realidade é um conjunto de fenômenos, entendidos como fenômenos que se auto completam e que se articulam entre si, mas que não chegam à totalidade complexa:

Se a realidade não tem determinações, o mundo é um mundo de fenômenos,
completos em si mesmos, que quando muito se articula uns com os outros.
Nesse caso, o estudo não pode chegar propriamente a explicações, mas
somente a descrições que precisem cada fenômeno, na sua inteireza e nas
relações (de superfície) que mantêm uns com os outros. [...] (CARDOSO,
1990, pp. 20-21)

Nesse sentido, entender a realidade como um somatório de fenômenos não permite chegar ao conhecimento sobre a realidade, pois a realidade, sem suas determinações, é abstrata, fragmentada, caótica, não trazendo consigo nenhum significado e nenhum sentido.

Negando esse método de conhecimento sobre a realidade econômica, Marx, segundo Cardoso (1990), afirma que o método científico correto para o conhecimento sobre a realidade é aquele que começa no conhecimento abstrato, teórico, buscando o conhecimento concreto sobre a realidade, conhecimento concreto que significa entender a realidade a partir de suas determinações. É o destaque dado às determinações que constrói o conhecimento sobre a realidade como um "concreto de pensamento".

Para Cardoso (1990, p. 23), ao afirmar que o conhecimento começa no abstrato teórico para chegar à concretude do real, o que Marx está sugerindo é um "procedimento novo, do abstrato (determinações e relações simples e gerais) ao concreto (que então não é mais "a representação caótica de um todo" e sim "uma rica totalidade de determinações e de relações diversas")". Considerando, então, esse pressuposto metodológico, a possibilidade de conhecer a realidade está na explicitação das determinações da realidade, condição de concretude da realidade: "O caráter de concreto está estreitamente vinculado ao de determinação. $O$ que conta de fato são as determinações. Atinge-se o concreto quando se compreende o real pelas determinações que o fazem ser como é." (Cardoso, 1990, p.24). Nesse sentido, entende-se que as determinações são concretas e reais, embora como categorias que explicam a realidade são objetos teóricos, reconhecidos pela ação do pensamento.

\begin{tabular}{|c|}
\hline Rovista Dialectus \\
\hline
\end{tabular}


Definindo o procedimento metodológico como sendo do abstrato teórico para o concreto, o ponto de partida está no pressuposto de que a condição de concretude da realidade não está em ser uma realidade visível, percebida pelos sentidos, pois não é porque se tem consciência da realidade pelos sentidos que a realidade é concreta. Sendo assim, Cardoso (1990, p. 24) afirma: "não basta ter realidade para ser concreto".

Essa trajetória do abstrato para o concreto permite conhecer a realidade quando são destacadas as determinações da realidade, fazendo da realidade, um novo concreto, concreto de pensamento: "esse concreto é um concreto novo, porque pensado. É um concreto produzido no pensamento, para reproduzir o concreto real ('as determinações abstratas conduzem à reprodução do concreto por meio do pensamento')". (Cardoso, 1990, pp. 23-24). No entanto, o conceito de "concreto de pensamento" não compreende que a realidade seja uma construção idealista, uma criação do pensamento - uma construção teórica. A realidade existe, é exterior à consciência e independente do pensamento como afirma a tese materialista por excelência: "O concreto produzido pelo pensamento não é o próprio real. A atividade do pensar não produz senão pensamentos (ideias, conceitos) no campo que lhe é próprio, que é o campo das abstrações. A atividade do pensar não é capaz de produzir realidades. [...]" (Cardoso, 1990, p. 29). Como consequência, o que a categoria "concreto de pensamento" informa é que existe uma distância entre a realidade e o objeto teórico, ou seja, entre o campo do real e o campo do teórico, distância que faz com que a realidade não seja, imediatamente, objeto teórico, à condição de objeto científico quando considerada como "síntese de múltiplas determinações.

\section{Considerações finais.}

Embora toda a crítica que Marx (1974) fez ao método científico da economia clássica, examinada e explicada minuciosamente por Cardoso (1977, 1990), não diga respeito ao conhecimento geral, e, portanto, não traz indicações diretas, objetivas e mediatas para a pesquisa em educação, a contraposição a um conhecimento científico que partiria do exame da realidade sensível e a afirmação do conhecimento da realidade como "síntese de múltiplas determinações" - determinações que afetam os sujeitos em sociedade e que são configuradas no pensamento - são fundamentais na defesa de opções teórico-metodológicas que entendem que o trabalho de pesquisa é um trabalho de construção teórica do objeto de conhecimento, quando o conhecimento teórico faz do real objeto científico, quando o destaque dado às determinações faz da realidade, "concreto de pensamento".

O método de conhecimento sobre a produção material, considerado por Marx (1974) como o método científico correto, não nega a abstração, mas a possibilidade de abstrair a realidade de suas determinações históricas e sociais. As abstrações são necessárias para o conhecimento, pois o próprio conhecimento se dá no nível do pensamento, lida com abstrações. No entanto, quando as determinações - entendidas como resultado de um trabalho de abstração que consegue identificar as condições necessárias para a existência da realidade tal qual se apresenta - são desprezadas no trabalho teórico, a abstração que se faz da realidade é justo aquela que vai buscar reproduzir no pensamento a sua forma imediata, sendo uma abstração esvaziada de história, abstração que considera o real como "dado". Tal compreensão faz desaparecer a história, ou seja, faz desaparecer a totalidade concreta, deixando ficar uma realidade imediata abstrata, que não traz, em si, a possibilidade de ser objeto científico.

Entendemos que o reconhecimento do caráter histórico e social da produção, no caso da produção teórica de Marx, permitiram-lhe operar no plano racional com a

\begin{tabular}{|l|l|l|l|l|}
\hline Govista Dialectus & Ano 2 & n.5 & Agosto - Dezembro 2014 & p.140 - 150 \\
\hline
\end{tabular}


existência de modos de produção específicos a partir de determinadas sociedades e oriundas da história da humanidade e não da natureza e assim, explicar o indivíduo e a propriedade privada dos meios de produção como formas típicas capitalistas, formas sociais particulares e específicas. Entendemos também que esse reconhecimento, tributário da crítica teórica de Marx, pode ser estendido ao conhecimento científico da educação que tal como a produção, objeto particular da ciência econômica, não porta em si uma natureza, mas carece de explicação a partir do conhecimento de suas determinações que são também históricas e sociais.

\section{Referências bibliográficas}

CARDOSO, M. L. A periodização e a ciência da História - observações preliminares. Texto impresso. Rio de Janeiro: FGV, 1977.

CARDOSO, M. L. Para uma leitura do método de Karl Marx - anotações sobre a "Introdução" de 1857. Cadernos do ICHF. Niterói: UFF, n. 30, setembro 1990.

MARX, K. Contribuição para a crítica da economia política. Lisboa: Editorial Estampa, 1974, p. $228-237$. 